\title{
TIP TARIHII
}

\section{İZMIR'DE YAYINLANAN TIP DERGILLERININ TARIIHÇESİ \\ 3. Dergilerin Billimsel Standart ve Kaliteleri}

THE HISTORY OF MEDICAL JOURNALS PUBLISHED IN IZMIR

3. The Scientific Quality and Standarts of the Journals

Eren AKÇIÇEK Ragip KAYAR Hidayet ÇATAL

\section{SUMMARY}

Only few of the 14 medical journals published in Izmir have been found uniform (2), to have appropriate references to Index Medicus (1) and to have good year, volume and number correlation (2).

Acceptance rate of papers is above 90 percent for 10 journals. This rate is 100 percent for 5 joumals.

There are only $6(\% 43)$ journals in which the number of peer-reviewers outnumbers the in-home reviewers. 35.8 percent of 724 published papers are from outside the institution and 13 percent of papers are from outside the city.

Almost any of the joumals - with only one exception- do not publish an editorial comment, letter and opposite opinion (secondary discussion).

These results have shown that there are not mostly scientific standarts and quality control in the periodicals published in Izmir.

(Key Words: Evaluation, Level, Science)

\section{ÖZET}

İmir'de yayınlanmakta olan 14 derginin pek azınm makale düizeni tektip, kaynaklari Indeks Medikus'a uygun ve yıl-volüm-sayfa ilişkisi doğru bulunmuştur (sırasıyla 2, 1 ve 2 dergi).

Dergilerin $10^{\prime}$ unda makale kabul oranı \% 90'm üstündedir. Beş dergide bu oran \% 100 dürr. Dıs incelemecilerin iç incelemecilerden sayıca üstün olduğu dergi sayısı yalnızca 6 dır. Dergilerdeki makalelerin \% 35.8'i kurum dışından, yalnızca \% $13^{\prime}$ ü Izmir disından gönderilmiş çalışmalardir.

Dergilerin bir istisna dışında 13'ünün editöryel yorum, mektup ve ek tartışma yayınlamadıkları gözlenmiştir.

Bu sonuçlar Izmir deki tup dergilerinde henüz bilimsel yayın standartları ve objektif kalite denetiminin yaygınlaşmadiğını düşündürmektedir.

(Anahtar Sözcuikler: Bilim, Değerlendirme, Denetim, Düzey)

\footnotetext{
Gastroenteroloji Kliniği (Uz. Dr. E Akçiçek)

Ege Tip Fak. 35100 Bornova - IZMIR

1. Gonel Cerrahi Kliniği SSK Topocik Hastanosi 35120 - IZMiR

(Doç. Dr. R Kayar, Kli. Şefi, Dp. Dr. H Gatal)

Yazışma : Dr. R Kayar
} 
Bilindiği gibi yıllardır ülkemizde hekimlerin literatürü yeterince izlemedikleri eleştirilir. Hekimler de kendilerini olanaksızlıkları (ekonomik, yabanci dil bilmeme) ve zaman darlığı ile savunsalar da gayet ucuz olan kendi dillerindeki dergileri niçin izlemedikleri çok sağlıklı olarak ortaya konmuş değildir. Üstelik yerli yazarlarm dahi çallşmalarında yerli dergileri izlemedikleri -kaynaklarinda yerli çalışmalara ender olarak yer verdikleri için- anlaşllmaktadir.

Bu durumun çok değişik boyuttaki etkenleri (Türk Tip Indeksi olmayısı en sılk neden olarak gösterilir) arasinda; sunulan biilimsel materyalin kalite ve standardinın ne derece rol oynadı̆ı̆ ilgimizi çekmiştir. Üstelik bazı çevrelerin de yerli çalışmalarm. kalite ve inanılırlığı konusunda ciddi (belki biraz önyargılı) kuşkulları bulunmaktadir.

Okuyucu ve yerli araşturmaciyı, yerli dergileri izlememekle suçlayabilmek için önce yeterli kalite ve düzeyde bilgi sunup sunulmadığından emin olmak gerekir.

Bu düşüncelerle yallnızca ilimizde -diğer dergilere erişme sorunu nedeniyleçlkmakta olan 14 tup dergisi bilimsel kalite ve standartlar bakımından değerlendirilmiştir.

\section{GEREC VE YO̊NTEM}

Izmir'de halen yaymlanmakta olan Tip Dergilerinin tarihçe, teknilk özellik ve olanakları çalışmamızın 2. bölümündle (SSK Tepecilk Hastanesi Dergisi 1992; 2 (2): 178-86) geniş bir şekilde incelenmiş bullunmaktadir.

Bu bölüimde ise Izmir'de yayinlanmakta olan 14 Tip Dergisinin editörlerine gönderilen ikinci bir anket formundaki (Tablo-1) yamitlar ve 1991 ve/veya 1992 yillarinda bu dergilerin basılmış olan tüm sayılar (bazı dergiler, bazı sayılarını henüz basmamıştur) incelenmektedir. Basilmış sayılarin incelenmesinde gözetilen noktalar Tablo-2'de verilmektedir.

Gerek anket sorularinin oluşturulmasında gerekse basılmış eserlerin değerlendirilmesinde dikkate allnacak standart kri-
TABLO -1: Editörlerce Doldurtulan Anket Sorular!:

1- Yayın Kurulunüzda;

a) başvuran her konudaki çalışma için yeterli branş uzmanı var mıdır?

b) Kurumunuz dişında branş uzmanı var midir, sayilari?

2. Son iki yılda bilimsel gerekçeyle reddedilen makale sayısı?

3- Kurum dişı uzmanlara danışıyor musunuz?

4- Otoritelere yazı Ismarlar misınız?

5- Editöryel yorum yayınladınız mi?

6- Son 2 yılda yayınladığınız bilimsel mekrup sayısı?

7-Karşı görüş (Tartışma) yayınladınız mı?

terlerin belirlenmesinde başvuru kaynağ olmadı̆̆ı için problem doğmuştur. Yazarlar tarafindan bu kriterler oluş̧turullurken varolabilecek birçok kriter arasından en objektif ve pratik yararı olanların seçilmesine gayret edilmiştir.

\section{SONUC VE BULGULAR}

\section{A - Baski Tarihi:}

4 dergi dişında (NBD, IÇHTB, UED, SSKTHD) bildirillmediğinden baski gecikmelerini belirlemek ve derginin düizenli çıkışı hakkında bir kanaat edinmek olanaksızdir.

B- Yanlış diizeltme, dizgi, baskı hatası:

Ciddi bir baskı ve dizgi hatası saptanmamıstur. Yanlış düzeltme (aynı veya sonraki sayıda) yalnizca 3 dergide (MJEU, SHD, SSKTHD) go̊rülmüştür.

C- Y1/Volum/Sayı/Sayfa iliskileri (TABLO-4):

a) İçindekiler bölümünde yeralmadı̆ğ 5 dergi

b) Makale başlığında yeralmadığ1 1 dergi

c) Cildinin sırt kısmindä yeralmadığı 10 dergi vardir.

D- Tektiplilik (uiniformite):

- 14 dergiden yalnizca 2'si (DETFD ve SSKTHD) tek düzende basilmiş, geri kalan- 
TABLO-2: Derginin içerik ve bilimsel kalite ve Denetimlerini değerlendirirken dikkate alınan kriterler:

A) Baskı Standartları:

1- Baskı tarihi (bildirme ve sayı ile uyumu)

2- Tek tiplilik (üniformite)

3- Dizgi hatası (rasgele 2 sayfadaki hata sayısı)

4- Baskı hatası (yazının bölüm ve bağlantularındaki hatalar)

5- Yanlıs düzeltme (bir sonraki veya aynı sayıda)

6- Yı/Nolüm/Sayı/Sayfa ilişkileri :

a- Sayfa numaralaması

b- Belirtildiği yer:

i- Içindekiler

ii- Cilt sırtı (raf görünümü)

iii- Makale başlık sayfası

B) Bilimsel Kalite Standard!:

1. Editöryel Yorum sayısı

2- Bilimsel mektup ve yanit sayısı

3- Karşıt görüş (Tartı̧ma) yayınlama

4. Kurum dışı danışma oranı (objektivite)

5- Bilimsel gerekçeyle reddedilen makale oranı.

6- Makaledeki kaynaklar

a- Indeks Medikus'a uygunluk

b- Kendi kurallarına uygunluk

c.- Ulaşımayan kaynakların (tebliğ, tez, kişisel görüşme..) eliminasyonu

7. Çeviri.yayınlama (Orijinallik)

c) Okurla lletişim Standartlar!:

1. Kurum dişından ve bölge dişından gönderilen makale sayısı (coğrafi yaygınlık)

2- Ismarlama yazilara yer verme

3- Konu-yazar indeksi (yillik ve toplu)

4- Yeni çikan kitap ve dergilerin duyurulması

5- Bilimsel toplantı ve haberler

6- Literatürden seçmeler (çeviri)

7. Abone formu

larda az veya çok farklilıklar görülmüştür TÁBLO-5). Óneğin Gereç ve Yöntem yerine bazen Materyal ve Metod, bazen sadece Metodlar ... denmesi gibi.

\section{E- Kaynaklarm diizeni (TABLO-5):}

14 dergiden yalnzca 3 'ünün (DETFD, IGHD, SSKTHD) Indeks Medikus kural-
TABLO-3: Izmir'de Yayınlanan Dergilerin Isim Kısaltmaları

Dergi

Ege Tip Dergisi

Kisaltma

ASS Izmir Devlet Hastanesi TIp Dergisi IDHTD

Spor Hekimliği Dergisi

Türk Parazitoloji Dergisi

SPHD

9 Eylül Üniv. Tip. Fak. Dergisi

Nörolojik Bilimler Dergisi

TPD

Izmir Çocuk Hastanesi Tip Bülteni

Izmir Göğüs Hastanesi Dergisi

Infeksiyon Dergisi

DETFD

NBD

IÇHTB

IGHD

Sağlık Hastanesi Dergisi

ID

Turkish Journal of Spinal Surgery

Medical Journal of Ege University

Ulusal Endokrin Dergisi

SHD

TJSS

MJEU

SSK Tepecik Hastanesi Dergisi

UED

SSKTHD

ların benimsediği görülmetedir. Bu 3 dergiden ise yalnizca birinin (SSKTHD) bu kuralları uygulayabildiği, diğerlerinin uygulayamadığı göruilmüstür. Indeks Medikus'a uymayan 11 dergiden ise yalnızca $3^{\prime}$ ü koyduğu kurallari uygulamıs, diğerleri bunu başaramamiştır.

TABLO-4: YıINolüm/Sayı/Sayła llişkileri ve Belirtildiği Yerler

\begin{tabular}{llll}
\hline Dergi Düzenli Içindekil. & $\begin{array}{l}\text { Makale Cilt } \\
\text { Baslığı. Sirtında }\end{array}$ \\
\hline
\end{tabular}

\begin{tabular}{lcccc}
\hline ETD & + & + & + & + \\
IDHTD & + & - & + & + \\
SPHD + & + & + & - \\
TPD & + & + & - \\
DETFD & + & + & - \\
NBD + & + & + & - \\
ICHTD - & + & + & + \\
IGHD - & - & + & - \\
ID & + & + & - \\
SHD & + & + & + & $-(*)$ \\
TJSS & + & - & - \\
MJEU - & + & + & - \\
UED + & + & + & - \\
SSKTHD + & + & + & +
\end{tabular}

(*) Cilt sirtı olmayan ince bir dergidir.

Tez, tebliğ ve kişisel görüşme gibi rutin ulaşılamayan kaynaklarin kaynaklarda yer verilmemesi gerekirken bu kurala yalnızca 3 derginin (ID, MJEU, SSKTHD) uyduğu saptanmiştır.

\section{F- Konu-Yazar Indeksi:}

Dergillerin 9'u yıllik indeks hazirlamakta iken, 5 yilı aşan 10 dergiden yalnızca 2'si 
TABLO - 5: Tektiplilik (üniformite) ve Kaynakların Belirtilmesindeki Standardizasyon KAYNAKLAR

\begin{tabular}{|c|c|c|c|c|c|}
\hline Dergi & Tektip & $\begin{array}{c}\text { Kurallara } \\
\text { IM }\end{array}$ & $\begin{array}{l}\text { Uygunluk } \\
\text { Kendine }\end{array}$ & $\begin{array}{l}\text { Ulaşımaz } \\
\text { Kayn. Yok }\end{array}$ & $\begin{array}{l}\text { Yillik } \\
\text { Konu- } \\
\text { Yazar } \\
\text { Indeksi }\end{array}$ \\
\hline ETD & - & - & + & - & + \\
\hline IDHTD & - & - & - & - & + \\
\hline SPHD & - & - & - & - & + \\
\hline TPD & - & - & - & - & - \\
\hline DETFD & + & + & - & - & - \\
\hline NBD & - & - & - & - & + \\
\hline IÇHTD & - & - & - & - & - \\
\hline IGHD & - & + & - & + & - \\
\hline ID & - & - & + & - & + \\
\hline SHD & - & - & - & - & + \\
\hline TJSS & - & - & $=$ & - & - \\
\hline MJEU & - & - & + & + & + \\
\hline UED & - & - & - & - & + \\
\hline SSKTHI & $1 D_{+}$ & + & + & + & + \\
\hline
\end{tabular}

toplu indeks başmış $(1,2)$ ancak $(1962-71)$ ve (1963-72) yillarinı kapsayan bu indeksleri sonraki yillara ait toplu indeksler izlememiştir.

3 editör bu konuda hazırlık yapıldı̆̆ını (IDHD, NBD, SHD) bildirmiştir.

G- Dergilerde Editöryel Yorum, Mektup-Yanıt, Tartışma Yayınlama

Tarafimizdan yapilan incelemede 14 derginin $13^{\prime}$ üinde üst otorite görüşünü temsil eden bir editöryel yorum, karşıt görüşleri yansitan bir mektup-yanit veya tartışma yayinlanmamiştır.

Anket sorularina verillen yanitlarda ise 3 dergi editörü(DETFD, NBD, IÇHTB) Editöryel Yorum ve Tartışma yayınladik-larını belirtmişlerdir. Bir editör (NBD) mektup yayınladığını billdirmiştir.

SSKTHD'de ise 1991 yllinda 1 mektup ve 1 yanit olmak üzere 2 yaziya ve 1992 yillinda ise 6 mektup 3 yanit, 2 editöryel yorum ve 3 tartışma olmak üzere 14 yazıya yer verilmiştir (TABLO-8).

H- Edito̊ruin beyanina dayanan red oran1:

Red oranı \% 10'un üstünde olanlar yalnizca 5 dergi vardir (TJSS, SSKTHD
TABLO-6: Kurum Dergilerinde

Danışman Dağılımı, Red Oranı

\begin{tabular}{|c|c|c|c|c|}
\hline \multicolumn{5}{|c|}{ Danışmanlar } \\
\hline & Diş & lç & D/loranı & RO $\%$ \\
\hline ETD & 2 & 7 & 0.29 & 5 \\
\hline IDHTD & 13 & 11 & 1.18 & 6 \\
\hline DETFD & $+?$ & 7 & $-?$ & 13 \\
\hline ICHTTD & 3 & 17 & 0.43 & 17 \\
\hline IGHD & 0 & 13 & 0 & 7 \\
\hline MJEU & 0 & 6 & 0 & 0 \\
\hline SSKTHD & 31 & 8 & 3.88 & 23 \\
\hline
\end{tabular}

İÇHTB, DETFD). Diğerlerinin kabul oranı \% 93-100 civarmoladir. 5 dergide, red oranı sifurdir (TABLO-6 ve 7).

TABLO-7: Branş Dergilerinde Danışman Dağılımı ve Red Oranı

\begin{tabular}{|c|c|c|c|c|}
\hline & \multicolumn{4}{|c|}{ Danışmanlar } \\
\hline & Diş & lç & D/l oranı & RO\% \\
\hline SPHD & 0 & 7 & 0 & 0 \\
\hline TPD & 0 & 5 & 0 & 0 \\
\hline NBD & 30 & 17 & 1.76 & 14 \\
\hline ID & 43 & 12 & 3.58 & 0 \\
\hline SHD(") & 3 & 2 & 1.5 & 0 \\
\hline TJSS & 6 & 7 & 0.86 & 30 \\
\hline UED & 12 & 10 & 1.2 & 0 \\
\hline
\end{tabular}

(") Sabit hekim kadrosu olmadığı için kurum dergisi kabul edilmedi.

\section{I- Kurum İçi / Diş1 Danışman Sayılları:}

Bu, iki bölüimde değerlendirilmiştir:

1) Kurumların çıkardığı dergiller (TABLO-6). 2) Kurum dişı kaynakların çıkardı̆̆ı dergiller (TABLO-7).

Kurum dergilerinin genellikle kurum içi danışmanların üstünlüğü (7'sinden 4'ünde) vardir.

Değerlendirilmenin objektivitesi bakımından dış danışmanların üstünlüğüinün önemi büyüktür. Bu üstünlük yalnızca bir dergide belirgindir (SSKTHD 8 iç 31 diş danışman).

Bir dergideki yazıların değerlendirilmesinde tarafsızlık (objektivite) için yazilarin en az yarisinin (\% 50) kurumla 
TABLO - 8: Yayınlanmış Makale Sayılarının Coğrafi Dağılımı

\begin{tabular}{|c|c|c|c|c|c|c|}
\hline & TMS & $\begin{array}{l}1991 \\
K D\end{array}$ & ID & TMS & $\begin{array}{l}1992 \\
K D\end{array}$ & ID \\
\hline ETD & 157 & $39(24.8)$ & $19(12.1)$ & 70 & $12(17.1)$ & $6(8.6)$ \\
\hline IDHTD & 115 & $51(44.3)$ & $10(8.7)$ & 106 & $49(46.2)$ & $13(12.3)$ \\
\hline DETFD & - & - & - & 45 & $1 \quad(2.2)$ & 0 \\
\hline ICHHTB & 33 & $19(57.6)$ & $5(15.1)$ & - & - & - \\
\hline IGHD & - & - & - & 28 & $8(28.6)$ & $3(10.7)$ \\
\hline MJEU & 67 & $11(16.4)$ & $7(10.4)$ & - & - & - \\
\hline SSKTHD & 45 & 21 (46.7) & $6(13.3)$ & 58 & $40(169)$ & $18(31)$ \\
\hline TOPLAM & 417 & $141(33.8)$ & $47(11.3)$ & 307 & $110(35.8)$ & $40 \quad(13)$ \\
\hline
\end{tabular}

TMS $=$ Toplam Makale Sayısi . KD=Kurum Dışı $\quad$ ID $=\mid$ zmir Dış।

TABLO - 9: SSK TEPECIK HASTANESI DERGISI'nin Iki Yillık Yayın Analizi

\begin{tabular}{l|cccc|cccc|c}
\hline Sayı & \multicolumn{7}{|c|}{1991} & \multicolumn{5}{c}{1992} & \\
& 1 & 1 & 3 & $T$ & 1 & 2 & 3 & $T$ & GT \\
\hline IY & 2 & 1 & 1 & 4 & 2 & 3 & 3 & 8 & 12 \\
DÇ & 1 & 1 & 0 & 2 & 0 & 0 & 2 & 2 & 4 \\
KA & 4 & 6 & 7 & 17 & 8 & 8 & 7 & 23 & 40 \\
OS & 4 & 9 & 5 & 18 & 6 & 4 & 5 & 15 & 33 \\
EY & 0 & 0 & 0 & 0 & 0 & 2 & 0 & 2 & 2 \\
Mektup & 0 & 1 & 0 & 1 & 2 & 1 & 4 & 7 & 8 \\
Yanıt & 0 & 1 & 0 & 1 & 2 & 0 & 2 & 4 & 5 \\
Tartışma & 0 & 0 & 0 & 0 & 0 & 0 & 3 & 3 & 3 \\
\hline Tip Tarihi & 1 & 0 & 0 & 1 & 1 & 2 & 1 & 4 & 5 \\
Tanı Ne & 2 & 0 & 0 & 2 & 0 & 0 & 0 & 0 & 2 \\
Kitap Tan. & 1 & 2 & 3 & 6 & 2 & 1 & 5 & 8 & 14 \\
\hline
\end{tabular}

$Y Y=$ Inceleme yazısı $\quad D C \zeta=$ Deneysel çalışma $K A=K l i n i k$ araştırma $O S=$ Olgu sunumu

$E Y=$ Editöryel yorum $\quad T=$ Toplam $\quad G T=$ Genel Toplam 
ilişkisi olmayan dış incelemeci/danışmanlarca değerlendirilmiş olması gerekir. Bu ise

$1: 1=1$ oranı verir. Bu oranı kurum dergilerinden yalnizca iki dergi (IDHM ve SSKTHD) tutturabilmiştir.

Branş derneklerinin (NBD, UED, TPD, ID gibi) çıkarmış olduğu dergilerde ise objektiviteyi değerlendirmek güçleşmektedir. Bu gibi dergilerde Editör ve Yayın kurulundaki isimler çeşitli kurum ve kesimlerde yer alırlar ve bu mekanizmanın ne ölçüde tarafsız yürüdügüünü kestirmek güçleşmektedir. Belki bu grup dergilerde objektivite değerlendirmesinde mektup ve ek tartışma gibi karşıt görüişlerin yer verilme oranlarının önemi artmalıdir.

\section{J- Derginin Ismarlama Yaz1 Oran:}

Bunu objektif değerlendirmek mümkün olmadığı için anket sorularına alınan yanıtlar dikkate alınmıştır. Yalnızca 5 dergi (NBD, SHD, İÇHTB, UED, SSKTHD) otoriteye yazı ısmarladı̆̆ını ve yayınladığını, diğer 9 dergi editörü ise hiç yazı 1 smarlamadığını billirmiştir.

\section{$\mathbb{K}$ - Çeviri Yayinlama:}

6 dergi (IDDHTD, SPHD, TPD, NBD, ID, SHD) çevirilere yer vermektedir. Orijinalite prensibini çiğnemeyen 8 dergi vardur.

\section{L- Yaymlanan Makalelerin Cografi} Dăgllim:

Bir kurum dergisinin ulaştığı, okunduğu ve olumlu bir yankı uyandırdığının bir göstergesi de kurum dışındaki yazarlara ait makalelerin bütün içindeki oranıdır. Yayınlanmış makalelerin coğrafi dağılımı ise - derginin coğrafi yaygınlığının bir göstergesi olarak allnabilir.

Branş dergileri genelde zaten çok merkezli otoritelerce kurulmuş ve yürütülmekte olduklarından coğrafi yaygınlık bakımından kurum dergileri ile değil kendi gruplarındaki diğer dergilerle kıyaslanmalıdırlar. Bir branş dergisi olan NBD'nin İzmir dışı makale oranı \% 26 olarak bildirilmiştir (6).

Bu görüşler doğrultusunda İzmir'de yayinlanan 7 kurum dergisinin 1991 ve 1992 yılında basılmış olan sayılarını inceleyerek kurum mensubu olan ve olmayan yazarlarin makale sayıları ile İzmir dışındaki kurumlara ait makale sayılarını belirledik (TABLO8).

Yine 1992 yıllunda 2 yaşını dolduran dergimiz sayı ve oran bakımından İmir d1şındaki yazarlarin yazılarına en çok yer ayıran dergi konumuna ullaşmiş bullummaktadir.

Dergimizin yayın analizinde ise bu konuma gelişimizin nedenlerini açılklayacak çok olumlu göstergeler vardır: yalnızca ilk iki yıl içinde 8 mektup, 5 yanıt, 3 ek tartışma, 2 editöryel yorum yayınlanmış olması çok renkli bir tartışma ortaminı yansıtmaktadır. Ayrica 13 yeni kitap tanıtımi da okuyucuya güncel bilgi aktarımı sorumluluğuna bir örnek ollarak alınabilir.

\section{M- Okuyucu-Dergi Yo̊netimi İetisimi:}

Yaptı̆̆ımı incelemede dergilerin yeni çıan kitap ve dergi, bilimsel toplantıların (kongre, sempozyum, seminer, kurs) ve anma-onur yazıları, haberler gibi güncell bilgillerin genellikle aktarılmadığın saptadık. Yalnızca 2 derginin (Türk P D. SPHD) kitap ve bilimsel toplantı duyurusu yaptıkları öğrenildi. Hiçbir dergide -SSKTHD hariçabone formunun bulunmadı̆̆ 1 izlendi. SSKTHD ise düzenli olarak her sayıda yeni çıkan kitap ve dergileri, yapılacak kongre ve toplantuları billdirmekte, anma ve onur yazıları ile haberler yayınlamakta, abone formu sunmaktadir.

\section{TARTISMA}

Derginin bilimsel yayin standart ve kalitesi iki bölüme ayrılarak tartışılacak, üçüncü bölümde ise okuyucu ile iletişim üzerinde durulacaktır.

A) Dergilerde Billimsel Yayın Standartlarunin Dirzeyi:

Makale bölümlerinde (Özet, Summary, Giriş, Gereç ve Yöntem, Sonuç ve Bulgular, Tartışma, Kaynaklar gibi bölümlerin sıra, isim bakımindan tektipliliği) 14 derginin yalnızca ikisinin (DETFD, SSKTHD) tektiplilik (üniformite) prensibine uymakta olduğu 
saptanmiştrr.

Yine yalnuzca 1 dergide (SSKTHD) makalelerinin kaynaklari Indeks Medikus'a uyumlu ve düzenli olarak basılmaktadir (\% 7.1). Hayran ve ark. 72 yerli dergide kaynaklari Indeks Medikus'a uygun olanlarun sadece \% 13.9 olduğunu bildirmektedir (3). Ulaşılamayan kaynak basmama prensibini ise yalnizca 3 dergi uygulamaktadir.

Görüldüğü gibi İmir'deki dergilerimizin hemen tümü -birkaç istisna dişında-bilimsel yayın standartlarma yeterli özeni göstermemektedirler.

B) Yayınlanan Makalelerin Seçiminde Objektivite:

Kurum dışı danışmanların/kurum içi danışmanlara oranı, kurum dışından yazı kabul oranı, makale red oran, mektup, ek tartışma ve editöryel yorum gibi karşıt görüşlere yer verme billimsel objektiviteyi yansitan kriterler olarak ele alınmiştir. Değerlendirmelerde kurum dergilerinin genellikle içe dönük değerlendirme yapmakta oluşları, kurum dişından yazı başvuru oranlarının hayli düşük düzeyde seyretmesi ile paralel gitmektedir.

Red oranlarmun dergilerin 2/3'sinde \% 10 'un altunda oluşu 0 dergilerde yaym seçiminde ciddi "kriterler" konmadığmı telkin etmektedir.

Mektup, editöryel yorum ve ek tartışma gibi karşıt görüşlerin istisnai bir dergi dişmnda (SSKTHD) hiçbir dergide yer almadığını saptamış olmamı da çok ilginçtir. Kartoğlu ve arkadaşları da 63 yerli dergide yaptikları incelemede 3893 yayından 39'unun mektup (\% 1) olduğunu belirtmektedirler (4). Incelediğimiz dergilerde ki 724 bilimsel yaymdan yalnuzca $8^{\prime i}$ (tümü SSKTHD'dedir) mektuptur (\% 1.1). Aynı şekilde Özsoylu, 116 yerli tıp dergisi incelemiş ve mektuplarin çok az olduğunu vurgulamıştır (5). Urzan ve arkadaşları bir dergide yayınlanmış 329 jinekolojik makaleden yalnuzca 9'unun (\% 2.7) eleştiri ve yanit aldığın belirtmektedir (7).

Mektuplarin bazı yabanci dergilerde (Lancet) yaymlarm \% 50 sine kadar ulaşabilliğine dikkatleri çekmek isteriz.

\section{C) Okuyucu ile iletisim:}

Dergilerin hemen tamaminin -neredeyse istisnai birkaç dergi dişında- okuyucuya yeni çıkan kitap ve dergi ile bilimsel toplantı duyuruları gibi güncel bilgileri sunmadığı dikkati çekmektedir. Bu durum dergilerin aldıkları mektup sayısı ile adeta bir paralellik içindedir.

Yalnizca iki ylllik bir dergi olan SSKTHD'nin yayın analizine bakıldığında ise; tektipliliğe ve kaynakta indeks Medikus'a uygunluğun sağlandığı, kurum dişı danışman oranı en yưiksek dergi oluşu, buna paralel olarak kurum dışı ve Izmir dışı yaymlara en yüksek oranda yer verdiği görülmektedir. Derginin mektup, editöryel yorum ve ek tartışma yayınlayan tek dergi oluşu, yayın standartlarına gösterdiği titizlik kadar okuyucu ile iletişimi artiran kitap tanıtımı, toplantı ve diğer haberleri yayınlamakta gösterdiği çabanın bir ürünü olsa gerekir.

Bu çalışma Tup dergilerimizin genelde okunmak değil ünvan ve kadro sinavları için hazırlanmış çalışmaların basılması için çıkarıldıklarını gözler önüne sermektedir. Bu dergilerin çoğundaki red oranlarının (\% 10 'un altında) ve dis incelemecilerin oranlarının düşüklüğüu (\% 50'nin altında) makale kabulünün objektif denetiminde ciddi kuşkular uyandirmaktadir.

Ayrica incelenen dergilerde gerek yazarlar, gerekse editörler ve yayın kurulu üyelerinin okuyucu beklentilerini ve çoksesliliği yeterince dikkate almadıkları izlenimi uyandırmaktadır. Nitekim dergilerin büyük çoğunluğu kendi iç yapılarındaki yazarların çalışmalarını yayınlar hale gelmiştir (TABLO-8).

Bilimsel araştırmalarm en önemli safhası ve ürünü olan bilimsel makalenin uluslararasi standartlara uygun bir şekille okuyucuya erişmesinin sağlanması kadar güncel bilgi ve haberlerin de aynı ciddiyet ve özenle aktarılması bilimsel yayıncılığın en önemli görevlerinden biri olmalıdır. Ancak bunlardan sonra okuyucunun ve araştırma- 
cıların yerli kaynakları yeterli izlemedikleri konusunda olumsuz eleştiri getirilebilir. Yazarı, okuyucuyu ve bilimsel yayıncılığı teşvik edici genel önlemler ise ülkenin bilimsel politika ve olanakları çerçevesi içinde kalmaktadir. Ancak bu çerçevedeki sorunlara rağmen ülkemizde varolan çok sayıda değerli araştırmacilardan oluşan potansiyele işlerlik kazandirmak koşuluyla "Editöryel Yaklaşım Kalitesinin" yazar ve okuyucuyu tatmin ve yönlendirme konusunda daha olumlu etkileyeceğine dikkatleri çekmek isteriz.

\section{TEŞEKKÜR}

Anketimizi yanıtlayarak çalışmamız verilerinin önemli bir bölümünü oluşturan Sayın Editörler Prof. Dr. Emel Tümbay, Prof. Dr. Savaş Kültür, Prof. Dr. Necati Akgün, Prof. Dr. Mehmet Ali Özcel, Prof. Dr. Berrin Acar, Prof. Dr. Kamuran Kumral, Doç. Dr. Erol Mir, Op. Dr. Oktay Başok, Orhan Adall, Prof. Dr. Emin Alıcı ve Prof. Dr. Candeğer Yılmaz'a, ayrıca yakın ilgi ve desteklerini esirgemeyen Doç: Dr. Ramazan Ínci. Doç. Dr. Nezih Oktar, Doç. Dr. Meral Akın'a teşekkürlerimizi sunariz.

Bu yazının birinci ve ikinci bölümler:

I. Yayınlanması sona ermiş dergiler. SSK Tepecik Hast Derg 1992; 2(1) : 81-4.

II. Yayınlanmakta olan dergilerin teknik özellik ve olarakları. SSK Tepecik Hast Derg 1992; 2(2) : 178-86.

\section{KAYNAKLAR}

1. Günhan C. Izmir Deolet Hastanesi Mecmuast. 10 Yallek Fihrist (1963-72). Izmir. Karmca Matb. 1973.

2. Bayat AH, Özgüven Ö. Ege Ůniversitesi Tpp Fakiiltesi Mecmuast Birinci 10 ynl Filnristi (196271). Izmir, Ege Üniv Matb, 1977.

3. Hayran O, Kayhan M. Yerli ve Yabanca Tip Dergileri. Sağllk ve Toplum 1990; (4) : 61-3.

4. Kartoğlu Ü, Hoşgeçin K. Türkiye'de Tibbi Dergiler Sağlnk ve Toplum 1990; 53) : 38-40.

5. Özsoylu S. Turkiyede Tup Dergileri。Tp Alaninda Bilimsel Yaymlar Sempozyumu 30.9.1991 Istanbul Üniversitesi Cerrahpaşa Tip Fakulltesi TÜBITAK Tıbbi Araştırma Grubu, Ankara 1992: 6770.

6. Oktar N. Nörolojik Bilimler Dergisinin Ilk Alt Yilı. Nör Bil Derg 1990; 7 (1-2): 1-2.

7. Uran B, Erler A. Karaman AŞ. Kadın Doğum Dergisinin ilk 6 yilında yayinlanan 329 makalenin incelenmesi. Kadun Doğum Derg (Medikal) 1992; 8 (2) : 71-5. 